\title{
Second-degree Wenckebach type AV block due to block within the atrium ${ }^{1}$
}

\author{
Onkar S. Narula, Manfred Runge ${ }^{2}$, and Philip Samet \\ From the Division of Cardiology, Department of Internal Medicine, \\ Mount Sinai Hospital of Greater Miami, Miami Beach, Florida, and \\ the University of Miami, School of Medicine, Miami, Florida, U.S.A.
}

Two patients with a history of paroxysmal supraventricular tachycardia were analysed by His bundle and intra-atrial recordings. The electrocardiogram showed sinus bradycardia in I patient and sinus bradycardia with sino-atrial Wenckebach in the other. The conduction times through the $A V$ node and His Purkinje system were normal in both cases. The intra-atrial conduction time was slightly prolonged ( $55 \mathrm{msec}$ ) in one and normal (40 msec) in the other during normal sinus rhythm. In both cases with atrial pacing from high right atrium, the conduction time from the pacing impulse (PI) to atrial activation in the area of the $A V$ junction $(P I-A)$ progressively lengthened with increase in atrial pacing rate and finally classical second-degree Wenckebach type of block was manifested at cycle lengths of 460 and $465 \mathrm{msec}$. The pacing impulse to $Q R S$ interval (PI-R) showed a progressive increase before the blocked stimulus. The lengthening of the PI-R interval was due to progressive increase in the intra-atrial $(P I-A)$ conduction time. In the dropped beats, the pacing impulse was not followed by an $A$ deflection. This observation indicated Type I block within the atrium. Similarly, during induced premature atrial beats, the PI-A time progressively lengthened as the coupling interval was shortened. These findings were reproducible and were seen despite a fourfold increase in stimulus strength and changes in electrodes and site of stimulation along the lateral right atrial border. This study (I) shows second-degree Wenckebach block within the atrium; (2) supports the existence of sinoatrial Wenckebach; and (3) suggests the atrium as another possible site for re-entry and a cause for supraventricular tachycardia because of the degree of delay and block exhibited within the atrium.

It is well known that block during impulse transmission may occur at any site where a difference in functional refractory period is present or where decremental conduction occurs (Hoffman and Cranefield, I960; Cranefield, Hoffman, and de Carvalho, 1959; Cranefield, Klein, and Hoffman, I971; Singer, Lazzara, and Hoffman, 1967). Mobitz (1924) first defined the electrocardiographic criteria for the two types of second-degree atrioventricular (AV) block (Type I and II). The Type II block, commonly known as Mobitz II, has been clinically and experimentally localized to the His-Purkinje system (Donoso, Adler, and Friedberg, 1964; Kaufman et al., 1961; Watanabe and Dreifus,

Received 28 February 1972.

1 This report was presented at the 2Ist Annual Scientific Session of the American College of Cardiology, I-5 March 1972, Chicago, Illinois.

2 Present address: First Medical Clinic, University of Hamburg, Hamburg 20, West Germany.
1967; Narula and Samet, I970). In contrast, Wenckebach type (Mobitz I) of AV block is generally considered to occur in the AV node. Recent reports have also shown that the Wenckebach type of block may be observed within the His bundle and bundlebranches (Narula and Samet, 1970; Puech et al., 1970). Intra-atrial conduction defects have been known to cause first-degree AV block (Katz and Pick, 1956; Narula et al., 1971). Though second-degree block within the atrium has been previously proposed, it has not been documented (Phibbs, 1963).

The purpose of this study is to present the electrophysiological data in 2 patients who manifested the typical Wenckebach AV block secondary to blocked $P$ waves within the atrium itself, i.e. proximal to the AV node. It is also shown that in these 2 cases, the intra-atrial conduction time was rate-dependent and progressively increased with increase in rate. The evidence further shows 
some of the potential inherent fallacies of arrhythmia interpretations based solely on the duration of the PR interval in the surface electrocardiogram.

\section{Case reports}

Case I A 69-year-old white woman was admitted because of tachycardia. At the age of 17 , she was told she had a heart murmur. Episodes of palpitations, first noted at age 52, were controlled by quinidine administration. Digoxin $(0.25 \mathrm{mg}$ daily) was started at $6 \mathrm{I}$ because of exertional dyspnoea. Three weeks before admission, she stopped digitalis and quinidine therapy, whereupon recurrent tachycardias developed. On examination, she exhibited the typical findings of mitral insufficiency and stenosis. $X$-ray examination revealed cardiomegaly with left atrial enlargement and calcified mitral valve leaflets. The clinical impression was rheumatic heart disease, cardiomegaly, mitral stenosis and insufficiency, pulmonary hypertension, and pa:oxysmal supraventricular tachycardia, Class II-C.

The electrocardiogram on admission (Fig. I, 20 April I97I) showed supraventricular tachycardia (probably atrial tachycardia with 2: I AV block) with a ventricular rate of II5 a minute. The QRS complex was $0.09 \mathrm{sec}$ in duration with a normal axis. The next day, the ventricular rate was 95 a minute after digitalis therapy. Two days after admission, an electrocardiogram revealed sinus bradycardia (45 a minute). The PR interval was $0.18 \mathrm{sec}$ and the QRS complex remained unchanged (Fig. I, 22 April 197I).

On the sixth hospital day, a cardiac conduction study was performed to help guide future drug or possible pacing therapy. His bundle recordings and sinus node recovery time were obtained as described previously (Narula et al., 1970; Narula, Samet, and Javier, 1972). During the study, the sinus cycle length ranged from 1250 to 1400 msec. The PR interval was $175 \mathrm{msec}$. The control conduction times through the AV node (A-H) and His Purkinje system were 75 and 45 msec, respectively. The conduction time through the atrium was slightly prolonged $(55 \mathrm{msec})$ and suggested intra-atrial conduction delay. This was further confirmed during induced premature atrial beats and atrial pacing with $2 \mathrm{msec}$ pulse duration. During premature atrial beats, the conduction time from the pacing impulse in the high right atrium to atrial (A2) activation in the area of the AV junction progressively lengthened (from 90 to $160 \mathrm{msec}$ ) with increase in prematurity of the premature atrial beats (Fig. 2, Panel A to D). The absolute atrial refractory period, as measured by induced premature atrial beats at double the diastolic threshold was $425 \mathrm{msec}$ (Fig. 2, Panel E).

FIG. I Case I. Rhythm strip (20 April 197I) shows supraventricular tachycardia which is followed by normal sinus rhythm 2 days later (22 April 1971). The 12 standard electrocardiogram leads are shown below.

\section{$4 / 20 / 71$}

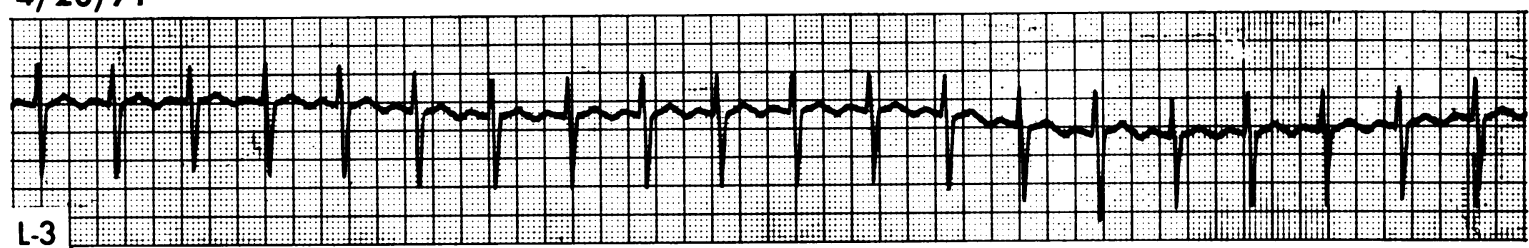

\section{$4 / 22 / 71$}

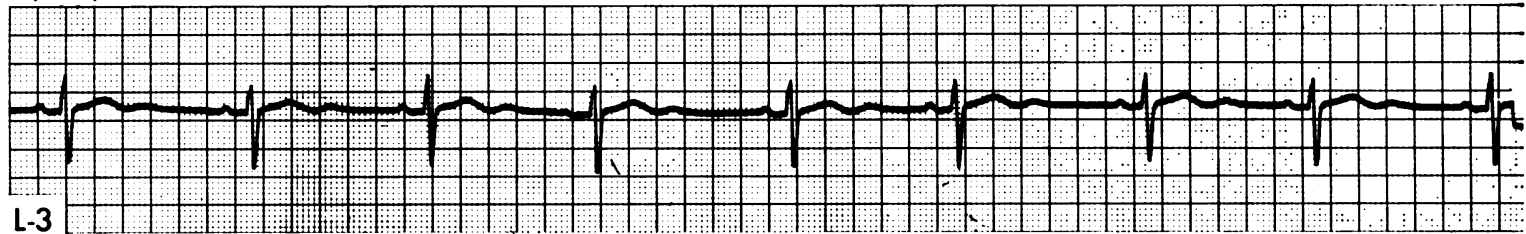

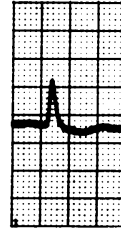

L-1

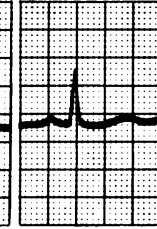

L-2

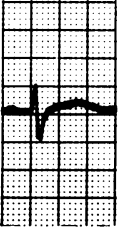

L-3

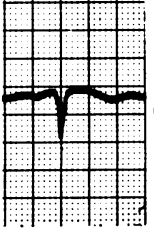

$a V_{R}$

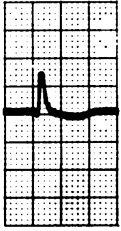

$a V_{L}$

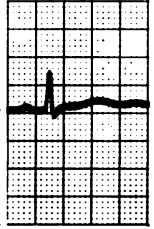

$a V_{F}$

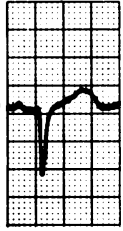

$V_{1}$

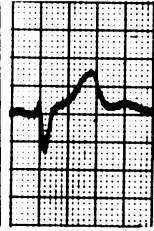

$V_{2}$

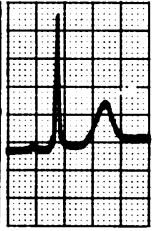

$V_{3}$

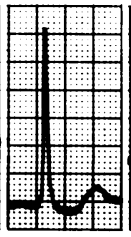

$V_{4}$

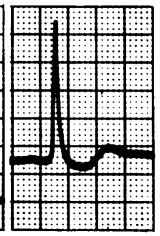

$V_{5}$

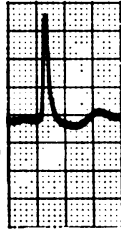

v. 


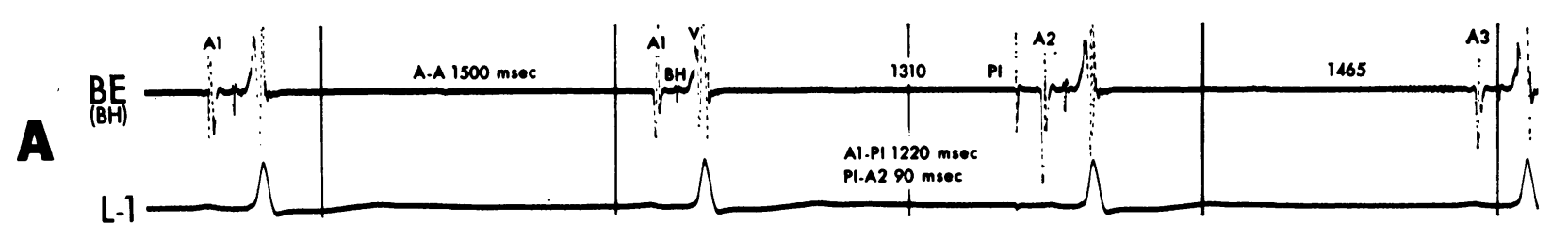

$\mathbf{B}$
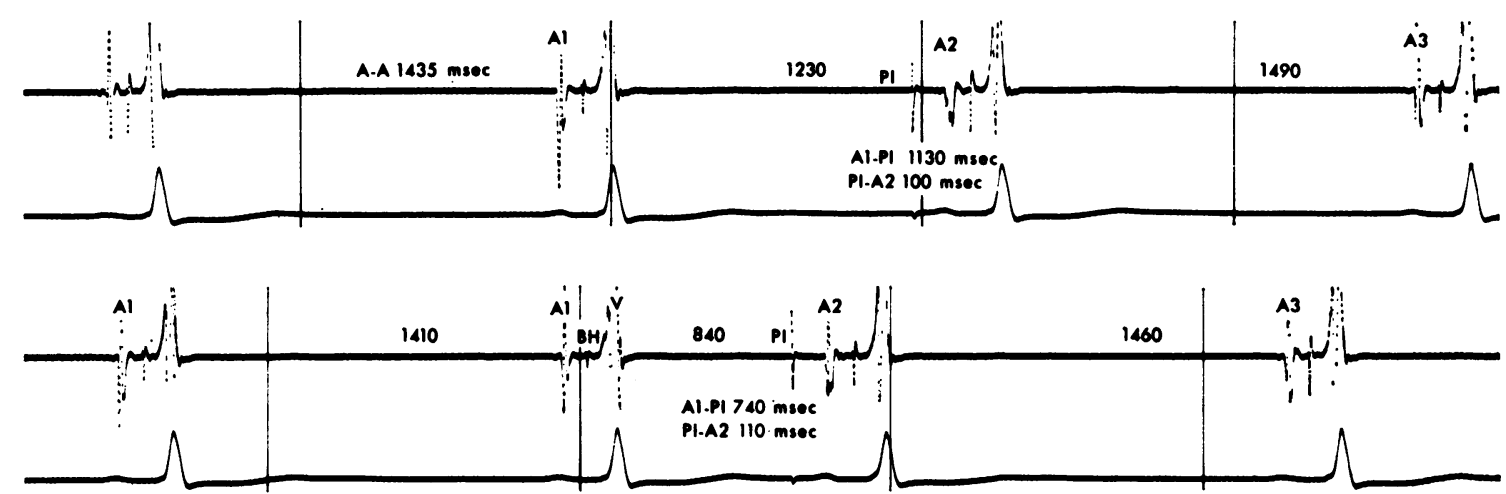

D
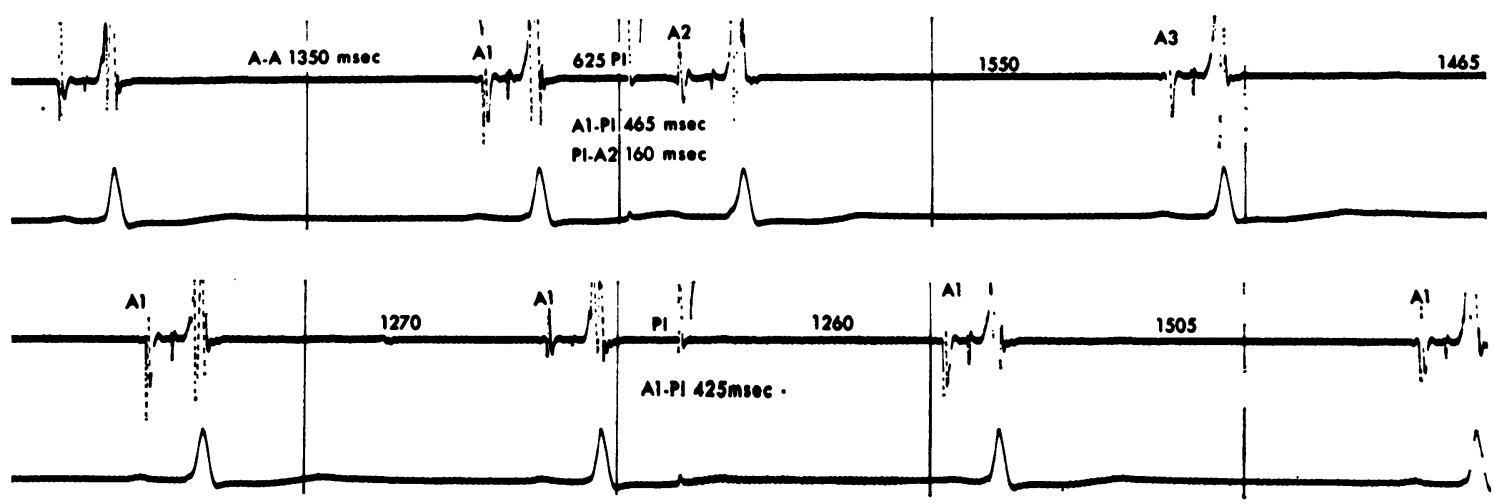

FIG. 2 Case I. Effect of prematurity of premature atrial beats on the pacing impulse (PI) to atrial $(A)$ activation $(P I-A)$ time. $(A-D)$ Simultaneous bipolar $(B E)$ recordings from the area of the $A V$ junction $(B H)$ with standard electrocardiogram lead $I$. During induced premature atrial beats, as the coupling interval $(A I-P I)$ was shortened from 1220 to $465 \mathrm{msec}$, the PI to premature atrial activation $(A 2)$ in the area of the $A V$ junction (PI-A2) time progressively lengthened from $90 \mathrm{msec}$ (Panel $A$ ) to $160 \mathrm{msec}$ (Panel $D$ ). (E) $A$ more premature stimulus $(P I)$ at a coupling interval (AI-PI) of 425 msec showed absolute refractoriness of the atrium. $A I=$ Atrial electrogram during normal sinus rhythm. A2 = Atrial electrogram during induced premature atrial beats. $B H=$ Bipolar His bundle electrogram. $V=V$ entricular activation recorded from the area of the $A V$ junction. Time lines in this and subsequent Figures $=I$ sec.

During atrial pacing, the PR interval progressively lengthened with increase in rate (cycle length from 1000 to $530 \mathrm{msec}$ ) (Fig. 3). The latter PR interval prolongation was caused by a lengthening of the pacing impulse-atrial (PI-A) time (from I IO to $180 \mathrm{msec}$ ) in addition to the increase in AH time. With further increase in atrial pacing rate (cycle length of $465 \mathrm{msec}$ ), Wenckebach type second-degree AV block was manifested within the atrium with an increase in pacing impulse-atrial time until finally the atrial com- plex was blocked and the pacing impulse (PI) was not followed by an $A$ wave (Fig. 4). The lengthening of the pacing impulse-atrial time was not progressive though it increased from ros to 330 msec preceding the dropped beat. The AH interval also exhibited an incomplete atypical Wenckebach phenomenon at the latter atrial pacing cycle length $(465 \mathrm{msec})$. The Wenckebach cycle in the AH interval was not complete (with a blocked $P$ wave in the AV node) because the simultaneous occurrence of Wenckebach 

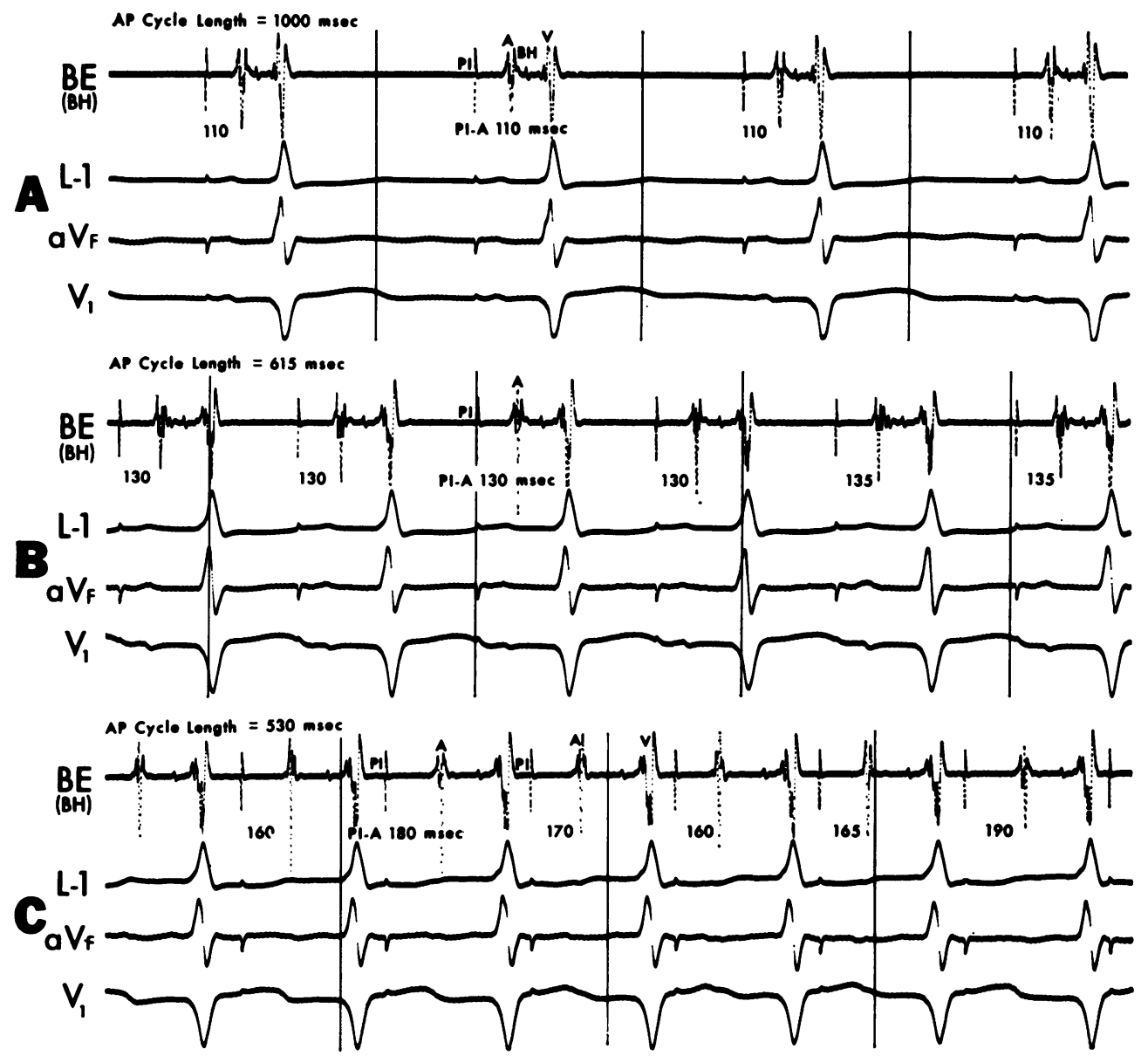

FIG. 3 Case I. Effect of increase in atrial pacing rate on $P I-A$ time. The right atrium was stimulated from the same site (high $R A$ ) as in Fig. 2. (A) Simultaneous recordings of $B E(B H)$ with 3 standard electrocardiogram leads $(I, a V F, V I)$. The PI-A time was IIo msec. (B-C) With progressive increase in atrial pacing rate (cycle length shortened to $530 \mathrm{msec}$ ), the $P I-A$ time progressively lengthened from $110 \mathrm{msec}$ (Panel $A$ ) to $180 \mathrm{msec}$ (Panel $C$ ) and contributed to the lengthening of the PI-R interval. The PI-A time varies slightly in Panel $C$.

periods within the atrium resulted in a transient increase in AA interval (slowing of atrial rate), and hence a transient decrease in $\mathrm{AH}$ conduction time. This case shows simultaneously two sites of Wenckebach block, i.e. incomplete Wenckebach in the AV node and complete Wenckebach within the atrium. It is of interest that the surface electrocardiogram does not show obvious dropped beats but simulates uninterrupted I: I AV conduction because of these two simultaneous sites of second-degree Wenckebach type of AV block (Fig. 4, Panel B). The second-degree block in this case can only be diagnosed on the basis of the intracardiac recordings.

The sinus node recovery time was measured as described previously and was conspicuously prolonged ( $2200 \mathrm{msec}+$ sinus cycle length). This observation suggested a sick sinus node (Narula et al., 1972). During ventricular pacing, retrograde conduction to the atrium was absent.

Case 2 A 73-year-old white woman was admitted because of a 2-year history of frequent palpitations despite quinidine administration but without digitalis. She was a known diabetic for the last 13 years and was well controlled with 32 units of Lente insulin daily. On examination, slight cardiomegaly and an atrial gallop sound were noted. She had discontinued quinidine ro days before admission.

The electrocardiogram had shown sinus bradycardia with rates ranging from 48 to 55 a minute for the past 18 months. The electrocardiogram recorded on 28 July I97I (Fig. 5) was compatible 

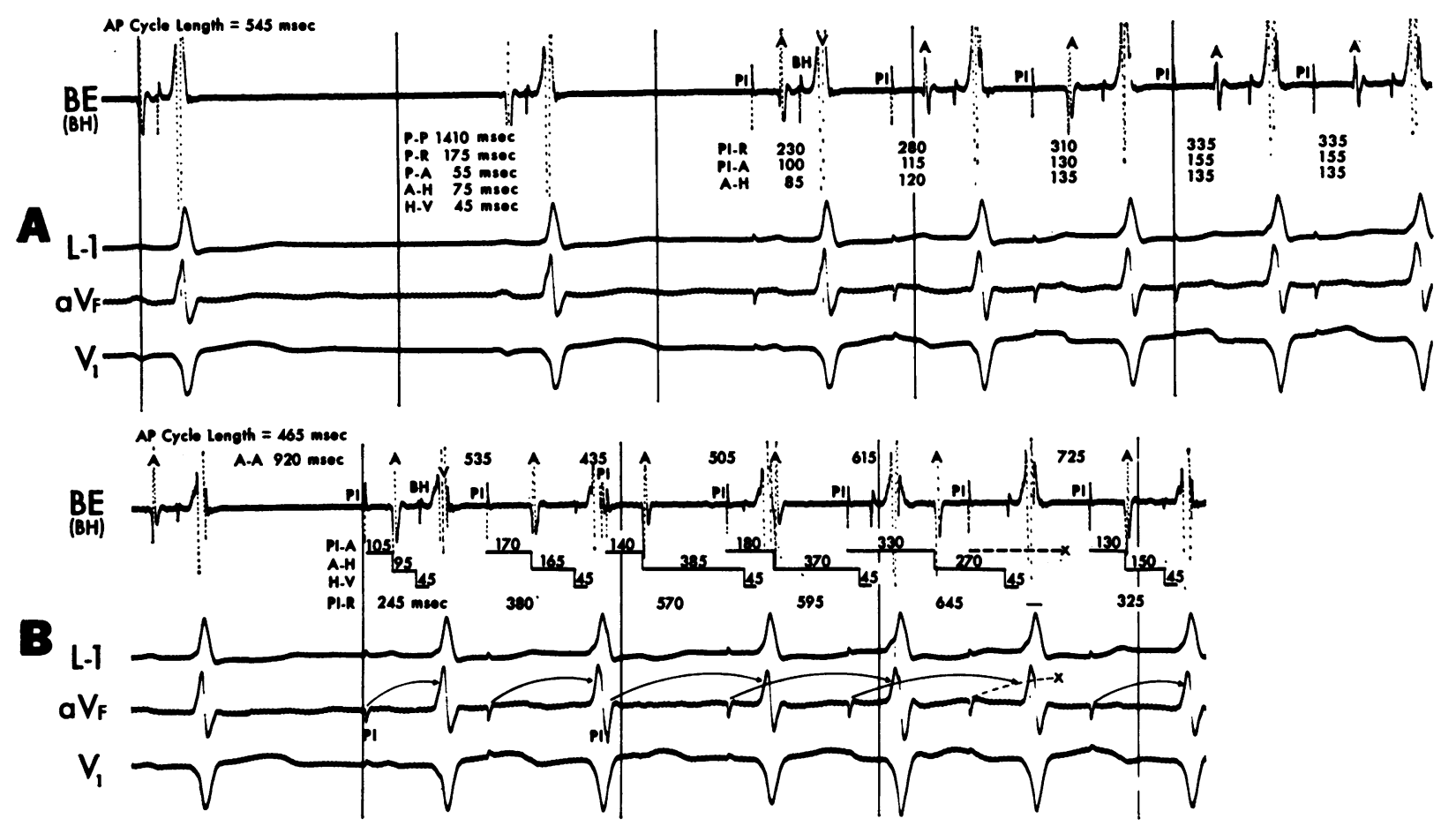

FIG. 4 Case I. During atrial pacing, second-degree Wenckebach type of block was localized in the atrium. $(A)$ Simultaneous recordings of $B E(B H)$ with 3 standard electrocardiogram leads ( $\left.I, a V F, V_{I}\right)$. First 2 beats with normal sinus rhythm show normal PR ( $\left.75 \mathrm{msec}\right), A H$ (75 msec), and HV (45 msec) intervals. The PA time ( $55 \mathrm{msec}$ ) during normal sinus rhythm was slightly prolonged. Latter half shows onset of atrial pacing at a cycle length of $545 \mathrm{msec}$. This is accompanied by an increase in PI-R (230 to $335 \mathrm{msec}$ ), PI- $A$ (IOO to $155 \mathrm{msec}$ ), and $A-H$ (85 to $135 \mathrm{msec}$ ) intervals before stabilization of these periods. (B) With increase in atrial pacing rate (cycle length $=465 \mathrm{msec}$ ), Wenckebach type of second-degree intra-atrial block was manifested. There was a progressive increase in PI-R from 245 to $645 \mathrm{msec}$ before a beat was dropped (6th PI). The PI-A progressively lengthened from 105 to $330 \mathrm{msec}$ before the 6 th pacing impulse is not followed by an $A$ wave indicating intra-atrial block. $A$ new cycle again starts (7th pacing impulse) with a short PI-A (I $30 \mathrm{msec}$ ) time. Simultaneously with an increase in PI-A time, the AH interval also lengthened progressively (95 to $385 \mathrm{msec}$ ) in a Wenckebach pattern (Ist to 3 rd paced beats). In the subsequent beats, the AH interval unexpectedly decreased to 270 msec ( 5 th paced beat) without completing the Wenckebach cycle. This resulted from a sudden decrease in $A A$ interval from $435 \mathrm{msec}$ (in the 4th $A$ ) to $615 \mathrm{msec}$ (6th $A$ ) despite $a$ constant atrial pacing rate due to an increase in PI-A time or Wenckebach in the atrium. This case represents a complete Wenckebach in the atrium (PI- $A$ interval) and a partial Wenckebach in the $A V$ node ( $A H$ interval).

with 4:3 sinoatrial Wenckebach. The PR and QRS intervals were 165 and $80 \mathrm{msec}$, respectively.

At the time of cardiac conduction study, the sinus cycle length ranged from I060 to II40 msec. The PR, PA, AH, and HV times were I65, 40, 80, and $45 \mathrm{msec}$, respectively. On atrial pacing with increase in rate (cycle length $600-$ $480 \mathrm{msec}$ ), the pacing impulse-atrial time progressively increased from 80 to $125 \mathrm{msec}$. With further increase in atrial pacing rate (cycle length 460 msec), second-degree Wenckebach block was seen (Fig. 6, Panel B). The PI-R interval pro- gressively lengthened from 215 to $335 \mathrm{msec}$ until the atrial pacing impulse was not followed by a QRS complex because of the intra-atrial block. The intracardiac recordings revealed a progressive lengthening of the conduction time from the pacing impulse to the atrial activation recorded from the area of the AV junction (PI-A = 70 to $150 \mathrm{msec}$ ) until the pacing impulse was not followed by an $\mathrm{A}$ wave indicating second-degree intra-atrial block. Similarly, during induced premature atrial beats, a progressive increase in pacing impulse-atrial time (80-145 $\mathrm{msec}$ ) was observed as the coupling interval was shortened 

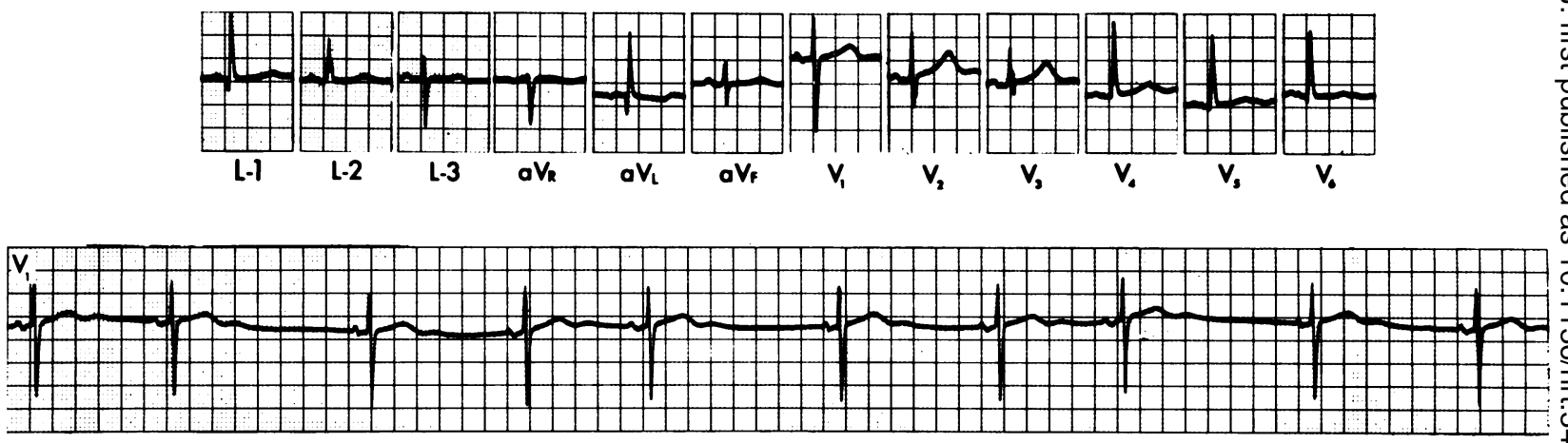

FIG. 5 Case 2. Twelve-lead standard electrocardiogram is shown above. Rhythm strip (VI) recorded on 28 fuly 197 I is highly suggestive of SA Wenckebach (4:3).

FIG. 6 Case 2. During atrial pacing, second-degree Wenckebach was localized in the atrium. $(A)$ Simultaneous $B E$ recordings from the area of the $A V$ junction $(B H)$ and 3 standard electrocardiogram leads $(I, a V F, V I)$. During normal sinus rhythm, the PR (I65 msec), PA (40 $\mathrm{msec}), A H$ (80 $\mathrm{msec})$, and $H V$ (45 msec) intervals are normal. (B) Atrial pacing at a cycle length of 460 msec shows Wenckebach second-degree block (4:3) localized within the atrium. The PI-R and PI-A progressively lengthen from 215 to 335 and 70 to 150 msec before a beat is dropped (4th pacing impulse). In the dropped beat, the pacing impulse is not followed by an $A$ wave, indicating block within the atrium proximal to the area of the AV junction. After the dropped beat, the Wenckebach cycle repeats itself.
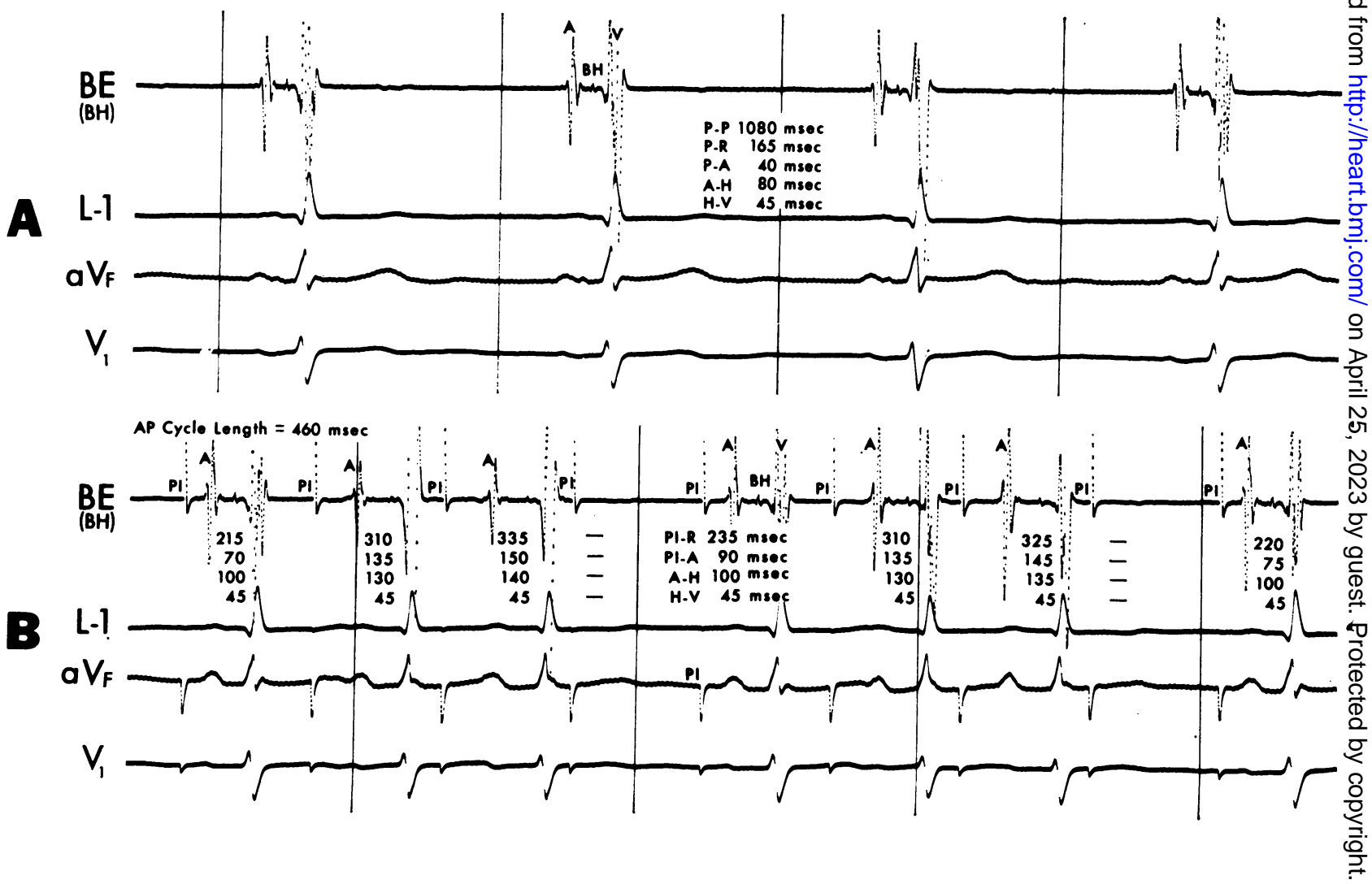
from Ioro to $470 \mathrm{msec}$ (Fig. 7). During normal sinus rhythm the right atrium was absolutely refractory to stimulation with induced premature atrial beats at a coupling interval of $385 \mathrm{msec}$ at double the diastolic threshold. During ventricular pacing, retrograde conduction to the atrium was absent. The sinus node recovery time was normal (400 msec + average sinus cycle length).

\section{Discussion}

The present study demonstrates a hitherto postulated but unproven site for the exhibition of second-degree Wenckebach block. It has been previously indicated that first-degree
AV block may result from intra-atrial conduction delays; this concept was recently confirmed in a study using intracardiac recordings (Katz and Pick, 1956; Narula et al., 1971). The latter study suggested that patients with abnormal intra-atrial (PA) conduction may exhibit progressive increment in PA (PI-A) time as the PP interval is shortened either by atrial pacing or by premature atrial beats. It was also conjectured that PA conduction defects, similar to defects in other segments of the conduction system, may cause higher degrees of AV block (Narula et al., 1971). The two cases in this study developed second-degree Wenckebach type

FIG. 7 Case 2. Effect of premature atrial beats induced from the high $R A$, in the region of the sinus node, on the PI- $A$ conduction time. $A-C$. As the coupling interval $(P-P I)$ was progressively shortened from $1010 \mathrm{msec}$ to $470 \mathrm{msec}$, there was a progressive lengthening of the PI- $A$ interval from 80 to $145 \mathrm{msec}$. The vertical broken line shows the simultaneous onset of the $P$ wave in the standard electrocardiogram leads and atrial activation in the area of the AV junction $((B E) B H)$. This raises the possibility of preferential conduction to the AV junction from the stimulation site.
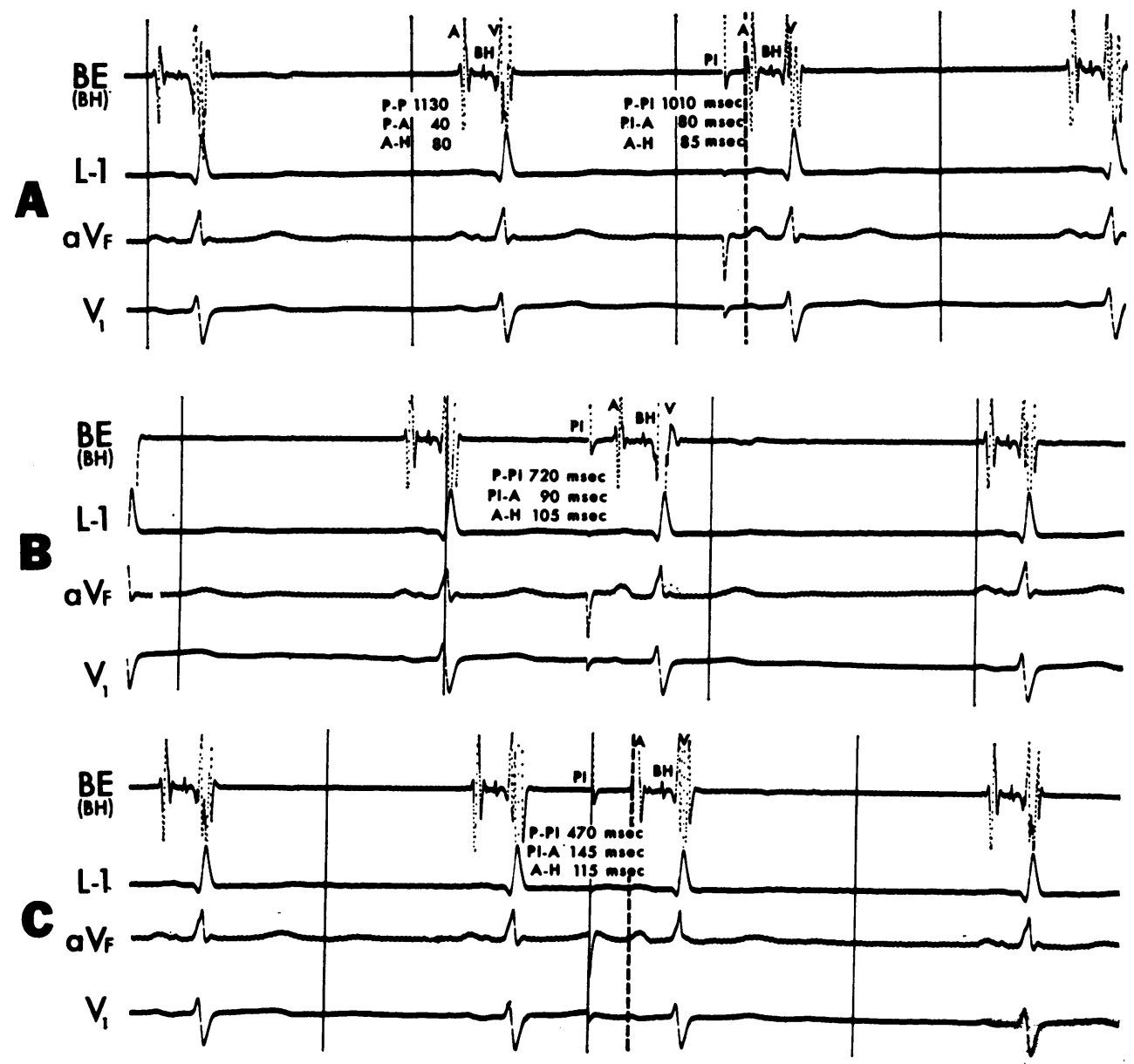
of $\mathrm{AV}$ block within the atrium during atrial pacing. The progressive lengthening of the pacing impulse to QRS (PI-R) interval was clearly shown to be caused in part by an increase in conduction time from the pacing site in the high right atrium to low right atrium (the area of the AV junction) until, finally, the pacing stimulus was not followed by an A wave (Fig. 6). This indicates block within the atrium. Case I (Fig. 4) is of interest because the study showed simultaneously two different sites of block, i.e. within the atrium and the AV node. The Wenckebach cycle in the AV node (AH interval) was partial or incomplete because of the delay and block in intra-atrial conduction before the impulse arrival at the AV junction. As a result, the AH interval, which at first progressively lengthened, suddenly shortened because the AA interval increased secondary to intra-atrial Wenckebach. These observations again indicate the limitations in the use of the standard electrocardiogram for the localization of the site of conduction defects (Narula et al., 197I).

Localization of the precise site of block within the atrium was not attempted and is beyond the scope of the present study as this would require close bipolar recordings throughout the atrium. It may be argued that the dropped beat is due to a pacing failure, resulting either from poor positioning or movement of the stimulating electrodes and an inadequate stimulus strength. These possibilities can be excluded for the following reasons. (I) To rule out the first possibility, the pacing electrodes were moved to various sites along the entire length of the lateral border of the right atrium; similar phenomena were observed at the varied pacing sites. (2) Catheter movement was excluded by constant fluoroscopic viewing during the sequence of atrial pacing. (3) The Wenckebach phenomenon was seen even at pacing with a stimulus strength of 4 times the threshold value and stimulus pulses of $2 \mathrm{msec}$ duration. (4) As the atrial pacing rate was decreased, $\mathrm{I}: \mathrm{I}$ atrial excitation and AV conduction resumed without other changes. The Wenckebach phenomenon was reproducible at will. With increase in pacing rate, the degree of block proportionately increased and eventually 2:I pacer stimulus - atrial depolarization block was manifested. (5) Finally, the progressive and classic increase in conduction time from the pacing impulse at high right atrium to the atrial depolarization in the area of the AV junction (PI-A) indicates that this phenomenon resulted from block within the atrium rather than a fortui- tous failure in pacing due to any of the above mentioned possibilities.

The underlying mechanism responsible for the development of intra-atrial block is of interest. Various possibilities should be mentioned. (I) In the dropped beat, the pacing stimulus occurred during the absolute atrial refractory period. This is probably not the case because the absolute atrial refractory period as evaluated by induced premature atrial beats during normal sinus beat (despite relatively prolonged sinus cycle lengths) was shorter than the interval at which the dropped beats occurred during pacing. The atrial refractory period during atrial pacing should be less than that during normal sinus rhythm since the pacing cycle length during second-degree block was less than 50 per cent of that during normal sinus rhythm. (2) The atrium was depolarized around the stimulating electrodes but the excitation failed to propagate because of conduction block in the adjacent atrium probably due to a disease process. This concept is supported by the progressive increase in the isoelectric interval from the pacing impulse to the onset of the $\mathrm{P}$ wave (Fig. 6). It may be that during the isoelectric period, the number of atrial fibres depolarized was not sufficient enough to produce a $\mathbf{P}$ wave on the standard electrocardiogram which requires depolarization of a large segment of atrial muscle. Normally the onset of the surface lead $P$ wave precedes the atrial depolarization recorded from the area of the AV junction (or low right atrium) by $25-45 \mathrm{msec}$ (Narula et al., 1970, Fig. I). However, in Case 2 (Fig. 7) during the induced premature atrial beats, the onset of the $P$ wave occurred at the same time as the atrial depolarization in the area of the AV junction. This suggests abnormal impulse transmission and probably segmented or localized atrial depolarization without a $\mathrm{P}$ wave in the electrocardiogram. An alternative explanation may be considered in the latter instance, namely that there is preferential conduction through specialized tracts from the point of stimulation to the $A V$ junction rather than conduction through the remainder of the atrium usually responsible for the production of the $P$ wave on the surface electrocardiogram (Sherf and James, 1969; Holsinger, Wallace, and Sealy, 1968). In any case, the atrial stimulus did not result in impulse propagation to the $A V$ junction and the ventricles causing second-degree AV block.

Several reports have described the existence of sinoatrial block (Type I and II) but various explanations proposed regarding its mechanism are controversial and lack experi- 
mental verification (Mackenzie, I902; Barlow, 1927; Eyster and Meek, 1917; Scherf, 1946, 1969; Greenwood, Finkelstein, and Monheit, 1961). Our study is an experimental model, with the atrial pacing stimulus representing the sinus node, which supports the concept of sinoatrial Wenckebach due to abnormal conduction between the sinus node and atrium. It is of interest that in Case 2, the sinus node recovery time, which is an indication of sinus node function as an impulse generator, was normal (Narula et al., 1972). The bradycardia in this case was probably secondary to sinoatrial block rather than the poor sinus node function, especially in view of the evidence of intra-atrial seconddegree block. Also at times, electrocardiographic findings of sinoatrial Wenckebach were observed in this patient (Fig. 5) though other possibilities may be entertained, i.e. increased vagal tone. However, in Case I, the sinus bradycardia was probably the result of both mechanisms, i.e. sinoatrial block and poor sinus node function because the sinus node recovery time was prolonged.

Previous studies from this laboratory have stressed the role of intra-atrial conduction (PA) delays in the production of first-degree AV block and have recommended division of - the measurement of conduction time from the onset of the $P$ wave to the onset of His bundle deflection into intra-atrial (PA or PI-A) and AV nodal (AH) intervals as opposed to the $\mathrm{PH}$, or PI-H intervals used by others (Narula et al., 1970, 1971; Damato et al., 1969). The latter studies have considered $\mathrm{PH}$ interval as representative of both atrial and AV nodal conduction times. The - present study, by showing first-degree and second-degree block within the atrium, reiterates the importance of dividing $\mathrm{PH}$ into $\mathrm{PA}$ and $\mathrm{AH}$ intervals so as not to overlook the role of intra-atrial conduction delays. The data also show that the PR interval may not provide an accurate measure of total - atrioventricular conduction time under special circumstances. Fig. 6 and 7 show that the atrial pacing impulse may be followed by a long isoelectric segment before the inscription of the $\mathbf{P}$ wave. This suggests that an impulse may develop and propagate in the atrium for significant periods without pro- ducing a deflection in the standard electrocardiogram in specialized circumstances. It is to be emphasized that the PR interval may be normal despite a first-degree block secondary to intra-atrial conduction delay, because the initial segment of the PR, as measured on the surface electrocardiogram, may be isoelectric due to intra-atrial conduction abnormalities. Similar conclusions were made in a recent study during open heart surgery using multiple stimulating and recording sites in the atrium under direct vision (Waldo et al., 1970). In the latter study, the maximum isoelectric segments between the pacing impulse and the onset of the $P$ wave ranged between 10-25 msec, depending upon the site of stimulation and the proximity of specialized intra-atrial tracts. In addition, it was pointed out that the polarity and shape of the $P$ wave could be altered by a few millimetres change in the atrial stimulation site (Waldo et al., 1970). The present study is in agreement with these latter findings and suggests that the shape of the $P$ wave and the PR interval is not a reliable means for localization of the site of impulse origin. In our cases, the prolongation of the PI-A time, despite varying stimulating sites, probably indicates a conspicuous degree of conduction defect.

In Case 2, during induced premature atrial beats, the onset of $P$ wave and atrial depolarization in the area of the AV junction occurred simultaneously with no measurable PA (PI-A) time. This and a previous study (Narula et al., 197I) suggest the following: (I) A short PA time, especially during ectopic atrial arrhythmias, may not delineate the complete intraatrial conduction time. Under these circumstances, atrial pacing in the area of the sinus node may be needed to evaluate true intraatrial conduction time. (2) In cases with sinus rhythm, the conduction time during atrial pacing from the region of the sinus node to the area of the AV junction may be an additional, clinically useful, parameter for the evaluation of the intra-atrial conduction.

One of the prerequisites for the mechanism of re-entry is a local conduction delay of sufficient magnitude during impulse transmission to enable complete recovery of the tissue at the subsequent time of impulse arrival at the site of its origin enabling a second passage of the impulse. The state for single or multiple re-entry beats is thus provided (Cranefield et al., 1959; Moe, Cohen, and Vick, 1963; Schuilenberg and Durrer, 1968; Wallace and Daggett, 1964; Han, Malozzi, and Moe, 1968). A recent study has indicated that AV nodal delay is usually a prerequisite for supraventricular tachycardias due to reentry. It was stressed that the AV node and not the atrium or the His Purkinje system is the essential site for re-entry (Goldreyer and Damato, I97I). However, the study merely showed that the re-entry site was proximal to the His bundle. The possibility 
that the atrium and not the AV node was the site of re-entry was not excluded by the experimental data of these investigators. Other experimental studies have, in fact, shown that the sinus node itself may be the site for re-entry (Wallace and Daggett, 1964; Han et al., 1968). Both patients in our study had a history of palpitations, and in Case $I$, atrial tachycardia was documented. Furthermore, in Case I, it was shown that Wenckebach type of block occurred in the atrium without dropped beats at the $\mathrm{AH}$ interval, i.e. in the AV node (Fig. 4). If the supraventricular tachycardia in this case was secondary to re-entry, then the probable site for re-entry was within the atrium rather than the AV node. The supraventricular tachycardias in the second case may also be explained on the same basis.

\section{References}

Barlow, P. (1927). The clinical occurrence of sinoauricular block. Lancet, $\mathbf{1}, 65$.

Cranefield, P. F., Hoffman, B. F., and de Carvalho, A. P. (1959). Effects of acetylcholine on single fibers of the atrioventricular node. Circulation Research, 7, 19.

Cranefield, P. F., Klein, H. O., and Hoffman, B. F. (1971). Conduction of the cardiac impulse. I. Delay, block, and one way block in depressed Purkinje fibers. Circulation Research, 28, 199.

Damato, A. N., Lau, S. H., Helfant, R. H., Stein, E., Berkowitz, W. D., and Cohen, S. I. (1969). Study of atrioventricular conduction in man using electrode catheter recordings of His bundle activity. Circulation, 39, 287.

Donoso, E., Adler, L. N., and Friedberg, C. K. (1964). Unusual forms of second degree atrioventricular block, including Mobitz type II block, associated with the Morgagni-Adams-Stokes syndrome. American Heart fournal, 67, 150.

Eyster, J. A. E., and Meek, W. J. (1917). Experiments on the origin and conduction of the cardiac impulse. VII. Sinoventricular and sino-auricular heart block. Archives of Internal Medicine, I9, II7.

Goldreyer, B. N., and Damato, A. N. (I97I). The essential role of atrioventricular conduction delay in the initiation of paroxysmal supraventricular tachycardia. Circulation, 43, 679.

Greenwood, R. J., Finkelstein, D., and Monheit, R. (196I). Sino-atrial heart block with Wenckebach phenomenon. American fournal of Cardiology, 8, 140.

Han, J., Malozzi, A. M., and Moe, G. K. (1968) Sino-atrial reciprocation in the isolated rabbit heart. Circulation Research, 22, 355.

Hoffman, B. F., and Cranefield, P. F. (1960). Electrophysiology of the Heart. McGraw-Hill, New York.

Holsinger, J. W., Jr., Wallace, A. G., and Sealy, W. C. (1968). The identification and surgical significance of the atrial internodal conduction tracts. Annals of Surgery, 167, 447.

Katz, L. N., and Pick, A. (1956). Clinical Electrocardiography. Part I. The Arrhythmias. Lea and Febiger, Philadelphia.
Kaufman, J. G., Wachtel, F. W., Rothfield, E., and Bernstein, A. (196I). The association of complete heart block and Adams-Stokes syndrome in two cases of Mobitz type of block. Circulation, 23, 253.

Mackenzie, J. (1902). The cause of heart irregularity in influenza. British Medical fournal, 2, I4II.

Mobitz, W. (1924). Uber die Unvollständige Störung der Erregungsuberleitung Zwischen Vorhof und Kammer des menschlichen Herzens. Zeitschrift für die gesamte experimenteelle Medizin, 41, I80.

Moe, G. K., Cohen, W., and Vick, R. L. (1963). Experimentally induced paroxysmal A-V nodal tachycardia in the dog. American Heart fournal, 65,87 .

Narula, O. S., Cohen, L. S., Samet, P., Lister, J. W., Scherlag, B. J., and Hildner, F. J. (1970). Localization of $\mathrm{A}-\mathrm{V}$ conduction defects in man by recording of His bundle electrogram. American fournal of Cardiology, 25, 228.

Narula, O. S., and Samet, P. (1970). Wenckebach and Mobitz type II A-V block due to block within the His bundle and bundle branches. Circulation, 4r, 947 .

Narula, O. S., Samet, P., and Javier, R. P. (1972). Significance of the sinus-node recovery time. Circulation, 45, 140 .

Narula, O. S., Scherlag, B. J., Samet, P., and Javier, R. P. (I97I). Atrioventricular block: localization and classification by His bundle recordings. American Fournal of Medicine, 50, 146.

Phibbs, B. (1963). Paroxysmal atrial tachycardia with block around the ectopic pacemaker. Circulation, 28, 949.

Puech, P., Grolleau, R., Latour, H., DuFoix, R., Cabasson, J., and Robin, J. (I970). L'enregistrement de l'activité électrique du faisceau de $\mathrm{His}$ dans les blocs A-V spontanés. Archives des Maladies du Coeur et des Vaisseaux, 63, 784.

Scherf, D. (1946). Experimental sino-auricular block. Proceedings of the Society for Experimental Biology and Medicine, 61, 286.

Scherf, D. (1969). The mechanism of sino-atrial block. American fournal of Cardiology, 23, 769.

Sherf, L., and James, T. N. (1969). A new electrocardiographic concept: synchronized sinoventricular conduction. Diseases of the Chest, 55, 127.

Schuilenberg, R. M., and Durrer, D. (1968). Atrial echo beats in the human heart elicited by induced atrial premature beats. Circulation, 37, 680 .

Singer, D. H., Lazzara, R., and Hoffman, B. F. (1967). Interrelationships between automaticity and conduction in cardiac Purkinje 'fibers. Circulation Research, 21, 537.

Waldo, A. L., Vitikainen, K. J., Kaiser, G. A., Malm, J. R., and Hoffman, B. F. (1970). The $P$ wave and P-R interval: effects of the site of origin of atrial depolarization. Circulation, 42, 653.

Wallace, A. G., and Daggett, W. M. (1964). Reexcitation of the atrium. 'The echo phenomenon'. American Heart fournal, 68, 661.

Watanabe, Y., and Dreifus, L. S. (1967). Second degree atrioventricular block. Cardiovascular Research, 1, 150.

Requests for reprints to Dr. Onkar S. Narula, Division of Cardiology, Department of Internal Medicine, Mount Sinai Hospital of Greater Miami, 4300 Alton Road, Miami Beach, Florida 33140, U.S.A. 